\title{
Endocrine changes, with special emphasis on oestradiol-17ß, prolactin and oxytocin, before and during labour and delivery in goats
}

\author{
W. B. Currie, R. C. Gorewit and F. J. Michel \\ Department of Animal Science, Cornell University Ithaca, NY 14853-4801, U.S.A.
}

\begin{abstract}
Summary. Jugular plasma concentrations of oestradiol- $17 \beta$, prolactin, progesterone and 13,14-dihydro-15-keto-prostaglandin F-2 $\alpha$ (PGFM) were measured at 2-h intervals during the last 4 days of pregnancy in 6 goats. During advanced labour and delivery, samples were obtained more frequently and assayed for oxytocin. The animals were housed in a barn with continuous dim lighting. A distinct pattern of oscillation in prolactin concentrations, with peaks during the late afternoon, was apparent during the last 3 days. Geometric means of peak concentrations doubled each day and became of longer duration; night-time nadir values remained low except during the last night before parturition. A progressive increase in oestradiol-17 $\beta$, with mean levels doubling every $36 \mathrm{~h}$, was apparent during the last 3 days. There was no sharp pre-partum increase in oestradiol-17 $\beta$. Correlated $(r=0.83)$ with the increase in oestradiol-17 $\beta$ was a gradual increase in PGFM and when the latter reached $\sim 1000 \mathrm{pg} / \mathrm{ml}$, the non-reversible decline in progesterone reflecting pre-partum luteolysis occurred. Subsequent changes in PGFM related closely to an approximately 20 -fold increase in the ratio of oestradiol-17 $\beta$ to progesterone until maximal PGFM levels of $26.5 \pm 4 \cdot 2 \mathrm{ng} / \mathrm{ml}$ were reached at delivery. Basal concentrations of oxytocin $(8-15 \mu \mathrm{U} /$ $\mathrm{ml}$ ) were measured before the last $60 \mathrm{~min}$ and markedly higher, though erratic, concentrations were detected at various times before appearance of the allantochorion. Maximal oxytocin values (range $180-1570 \mu \mathrm{U} / \mathrm{ml}$ ) occurred within minutes before or after delivery of the first fetus. The results suggest that increased pre-partum production of oestradiol-17 $\beta$, in addition to provoking sufficient release of prostaglandins to cause luteolysis, may modulate either the sensitivity or set-points for an endogenous rhythm in prolactin secretion at the end of pregnancy. The nature of the oxytocin changes suggests that, after labour has evolved sufficiently, delivery is precipitated by an abrupt increase in oxytocin secretion.
\end{abstract}

Keywords: goat; hormones; luteolysis; labour; parturition

\section{Introduction}

The goat is an example of species in which luteal secretion of progesterone is required at all stages for pregnancy maintenance and in which cessation of luteal function at term is a requirement for labour and parturition to occur. The complex of endocrine changes already described for the goat results from activation of the fetal adrenal cortex and maturational changes in the placenta (Currie \& Thorburn, 1977a,b). To link these changes in the conceptus to pre-partum regression of the corpora lutea, an increase in secretion of oestradiol-17 $\beta$ was presumed to provoke release from the maternal caruncles of prostaglandin (PG) F-2 $\alpha$ as the luteolytic factor (Currie et al., 1973, 1976). Only limited data have become available on pre-partum concentrations of oestradiol-17 (Umo et al., 1976; Flint et al., 1978; Davies et al., 1979) since our initial studies and their value is critically dependent upon the specificity characteristics of the assay employed. There is an enormous excess 
of oestradiol-17 $\beta$ over the $\beta$-epimer in the oestradiol fraction of the unconjugated and sulphoconjugated oestrogen pool (Thorburn et al., 1972; Currie et al., 1973; Umo et al., 1976). Because exogenous oestradiol-17 $\beta$, but not oestradiol-17 $\alpha$, is able to release PGF, to cause luteolysis and thereby induce premature parturition (Currie et al., 1976), it is likely that changes in the $\beta$-epimer are of greater physiological importance.

There is a substantial increase in prolactin concentrations in the dam (Buttle et al., 1972; Hart, 1972; Davies et al., 1979) before parturition, comparable to that of the increase in oestrogen secretion, as deduced from the studies cited above. The increase in prolactin, coupled with a shift in the relative influence of progesterone and oestrogens, is generally believed to provide the trigger for lactogenesis.

In this paper, we describe pre-partum changes in the jugular venous concentrations of oestradiol-17 $\beta$ and prolactin in detail. Changes in progesterone and 13,14-dihydro-15-keto-PGF$2 \alpha$ (PGFM) are also described. Finally, as there was opportunity to collect a large number of samples during advanced labour and delivery, we have obtained a reasonably complete description of the pattern of secretion of oxytocin at that time.

\title{
Materials and Methods
}

\begin{abstract}
Animals
Goats, of predominantly French Alpine breeding and of various ages, were brought to synchronous oestrus after withdrawal of vaginal sponges impregnated with $20 \mathrm{mg}$ fluorogestone acetate (Searle, Skokie, IL). The animals were artificially inseminated using mixed semen from several donor bucks, as part of a separate experiment. During pregnancy, the animals were housed indoors as a group under natural lighting and fed a hay-concentrate ration to requirements. The animals were moved to individual tie-stalls with loose straw bedding in another barn some 10-14 days before expected parturition. For the duration of sampling, the animals were in a barn that was very weakly illuminated with daylight and continuous low level incandescent lighting. During this time, animals had free access to water and a mineral-supplemented hay-concentrate diet that had a caloric density of $6.5 \mathrm{MJ} / \mathrm{kg}$ and was $16.7 \%$ in crude protein.

Polyvinyl chloride catheters $(0.86 \mathrm{~mm}$ i.d. and $1.27 \mathrm{~mm}$ o.d., Dural Plastics, Dural NSW, Australia) were inserted percutaneously into a jugular vein and placed so that $\sim 6 \mathrm{~cm}$ of catheter lay in the vessel. The lumen was filled with sterile heparinized saline (100 i.u. $/ \mathrm{ml}$ of $0.9 \%(\mathrm{w} / \mathrm{v})$ sodium chloride) and the proximal end of the catheter was fitted with a blunt needle and plug. The exteriorized portion was enclosed in a denim pouch with a Velcro closure, cemented to the neck. Blood was collected into $10-\mathrm{ml}$ heparinized syringes and transferred to polystyrene tubes, the inner surface of which had been coated with $10 \mu \mathrm{g}$ indomethacin, evaporated from an ethanolic solution. Samples were held in melting snow for the $5 \mathrm{~min}$ required to bleed all animals then plasma was separated by centrifugation and held at $-20^{\circ} \mathrm{C}$ until analysis. Each animal was sampled every $2 \mathrm{~h}$ for at least 7 days before parturition, and more frequently during advanced labour and delivery. The animals were totally familiarized to the personnel and handling and exhibited no obvious stress or aversion to the procedures, even during parturition.
\end{abstract}

\section{Radioimmunoassays}

Prolactin. Concentrations of prolactin were measured by an ovine prolactin radioimmunoassay (Butler et al., 1975) using ovine prolactin (NIH P S8, 28 i.u./mg) standards and ovine prolactin (LER-860-2) for preparation of ${ }_{125}$ I-labelled tracer. Radioiodination was performed as described by Shiu et al. (1973). Based initially on the findings of McNeilly \& Andrews (1974), we assume that it is meaningful to express concentrations in goat plasma in terms of sheep prolactin equivalents. Additionally, serial dilutions of a goat pituitary extract and goat plasma collected early post partum could not be shown to differ in slope $(P<0.01)$ from standard curves prepared from sheep prolactin. Assay sensitivity was $1.25 \mathrm{ng} / \mathrm{ml}$ and intra- and inter-assay coefficients of variation were $7 \cdot 3$ and $11.6 \%$. Prolactin concentrations in plasma from pregnant and parturient goats are distributed normally only after logarithmic transformation; the data presented here were log-transformed before calculating means and standard errors.

Oestradiol-17ß. Concentrations of oestradiol-17 $\beta$ were measured by a modification of the procedure of Fitzgerald \& Butler (1982) with antiserum GDN 244, some cross-reactivity data for which are provided by Korenman et al. (1974). Oestrogens were extracted from $400 \mu \mathrm{l}$ plasma into a single $4-\mathrm{ml}$ volume of benzene:toluene $(2: 1 \mathrm{v} / \mathrm{v})$. The residue after evaporation was transfered to mini-columns (Isolab, Akron, $\mathrm{OH}$ ) packed with $0.5 \mathrm{~g} \mathrm{LH}-20$ (Pharmacia, Piscataway, NJ) using two $250 \mu \mathrm{l}$ portions of benzene:methanol $(90: 10 \mathrm{v} / \mathrm{v})$. The loaded columns were washed with $1.5 \mathrm{ml}$ of the same solvent then the oestradiol fraction was eluted with an additional $2 \mathrm{ml}$ of the same solvent. This fraction, and standard amounts of oestradiol-17\% (Steraloids, Wilton, $\mathrm{NH}$ ) in ethanolic solution, were evaporated and 
redissolved in $100 \mu \mathrm{l}$ phosphate-buffered saline containing $0 \cdot 1 \%(\mathrm{w} / \mathrm{v})$ gelatin. A 1:50000 dilution of the antiserum $(100 \mu \mathrm{l})$ and 8000 c.p.m. of freshly purified $\left[2,4,6,7,16,17-{ }^{3} \mathrm{H}\right]$ oestradiol-17 $\beta$ (sp. act. $138 \mathrm{Ci} / \mathrm{mmol}$ : New England Nuclear, Boston, MA), also in $100 \mu \mathrm{l}$, were added and incubated for $4^{\circ} \mathrm{C}$ for $16 \mathrm{~h}$. Antiserum-bound radioactivity was separated by adding $1 \mathrm{ml}$ dextran-charcoal $\left(0.0225 \%\right.$ and $0.225 \% \mathrm{w} / \mathrm{v}$, respectively), incubating for $10 \mathrm{~min}$ at $4{ }^{\circ} \mathrm{C}$, centrifuging and decanting the supernatants. Radioactivity in the supernatants, blended with $4 \mathrm{ml} \mathrm{ACS} \mathrm{(Amersham,}$ Arlington Heights, IL), was measured at $25 \%$ efficiency over $10 \mathrm{~min}$ in a liquid scintillation spectrometer.

Cross-reactivity of the antiserum to oestradiol-17 $\alpha$ (Steraloids) was determined using a wide range of steroid concentrations evaporated from ethanolic stocks. Cross-reactivity of this antiserum against oestradiol-17 $\alpha$ was determined to be $0.0021 \%$, compared to oestradiol- $17 \beta$. Even this very weak cross-reactivity could be due to trace contamination of the reference preparation and the concentrations needed to compete with [ $\left.{ }^{3} \mathrm{H}\right]$ oestradiol-17 $\beta$ for antiserum binding are approaching the solubility limit of the steroid in assay buffer. The 50000 -fold selectivity for oestradiol$17 \beta$ over the $\alpha$-epimer eliminates any real concern regarding which steroid is being measured. Reliability of the extraction and chromatography steps was assessed by determining recoveries $(>93 \%)$ of $\left[{ }^{3} \mathrm{H}\right]$ oestradiol- $17 \beta$ added to a pool of goat plasma that had been stripped of endogenous steroids by prior incubation at $37^{\circ} \mathrm{C}$ with charcoal, then centrifuged and thoroughly filtered. Recoveries were assessed by routine inclusion of known concentrations of radioinert oestradiol-17 $\beta$ added to the stripped plasma and carried through the entire assay. Repeatabilities were monitored within each assay by replicated measurements and an array of blanks was included to assure quality control of the solvents. Comparisons of amounts measured against amounts added to stripped plasma $(0,3.07,33 \cdot 3 \mathrm{pg})$ gave an average recovery of $81.3 \pm 4.8 \%$. Sensitivity of the assay was usually $1.03 \mathrm{pg} / \mathrm{ml} \mathrm{but} 3.07 \mathrm{pg} / \mathrm{ml} \mathrm{could} \mathrm{always} \mathrm{be}$ distinguished from zero. Within- and between-assay coefficients of variation were $7.9 \%$ and $12 \cdot 2 \%$ respectively. The data were not adjusted for procedural losses.

Progesterone. Plasma $(100 \mu \mathrm{l})$ was mechanically extracted by shaking with $3 \mathrm{ml}$ petroleum ether (BP 40-60) and the phases were separated by freezing and decanting. Standards were taken from ethanolic stocks. The assay was as described by Fitzgerald \& Butler (1982); the only significant cross-reactivity was exhibited by $5 \beta$-dihydroprogesterone $(11.6 \%)$. Quality control was routinely monitored by including pools constructed from known amounts of radioinert progesterone (Sigma Chemical Company, St Louis, MO) added to bulk volumes of goat plasma that had been treated previously with charcoal. Overall recoveries of added progesterone were consistently between 91 and $94 \%$. The assay sensitivity was $156 \mathrm{pg} / \mathrm{ml}$ and intra- and inter-assay coefficients of variation were 6.7 and $12.5 \%$. Values were not adjusted for procedural losses.

PGFM. A procedure based on that of Cooke \& Homeida (1982) was used to measure PGFM. Plasma (25-100 $\mu 1$, depending upon expected concentrations) was diluted to $500 \mu \mathrm{l}$ with $12.5 \mathrm{~mm}$-citric acid, 4 ml diethyl ether from a freshly opened can were added and the tubes were vortexed. Phase separation was aided by placing the tubes in a forced air freezer for 30-60 min before decanting. Standard concentrations of PGFM (Cayman Chemical Company, Ann Arbor, MI) were prepared in assay buffer. The remainder of the assay was as described by Olson \& Hertelendy (1981). Quality control measures included the assay of water and diethyl ether blanks and the routine inclusion of pools constructed from charcoal-treated goat plasma containing known additions of radioinert PGFM. Recoveries varied between 83 and $87 \%$. In the method as used here, with $100 \mu \mathrm{l}$ samples, a concentration of $39 \mathrm{pg} / \mathrm{ml}$ was reliably distinguished from zero. Intra- and inter-assay coefficients of variation were 8.5 and $9.8 \%$. Samples from an individual were assayed in a single batch, but a portion of each set required reassay because of excessive concentrations. As in the other extraction assays, no correction was applied for procedural losses.

Oxytocin. The non-extraction radioimmunoassay of Gorewit (1979) was used with slight modifications (Wachs et al., 1984; Freeman \& Currie, 1985). The antiserum was the same lot as in the original study and was from CalbiochemBehring (La Jolla, CA). Mannitol-extended synthetic oxytocin, also from this supplier (29.2 U/mg), was used for standards and in preparation of ${ }^{125} \mathrm{I}$-labelled peptide. Concentrations greatly in excess of the range of the standard procedure were reassayed after diluting with charcoal-treated goat plasma to maintain constant plasma volume. Gorewit (1979) showed that charcoal treatment was completely effective in removing endogenous oxytocin.

A few samples containing very high concentrations of oxytocin were subjected to gel filtration on a column packed with Biogel P-10 (Biorad laboratories, Richmond, CA) and the eluted fractions were assayed (see Wachs et al., 1984, for details). Endogenous oxytocin was eluted with the same distribution coefficient as synthetic pharmaceutical preparations ( $1 \mathrm{mU}$ ), applied in phosphate-buffered saline or in charcoal-treated plasma.

Assay variability was assessed using replicated measurements of pools of goat plasma previously found to contain high, intermediate or low concentrations of endogenous oxytocin. Intra- and inter-assay coefficients of variation were $7 \cdot 8$ and $14.6 \%$

\section{Results}

Spontaneous parturition occurred on Day $152 \pm 2$ after artificial insemination and was uneventful except in Goat 239 which required manual assistance because of forelimb flexion of the fetus. Goat 244 delivered unobserved about 10-20 min after an inspection; samples taken within the last hour 


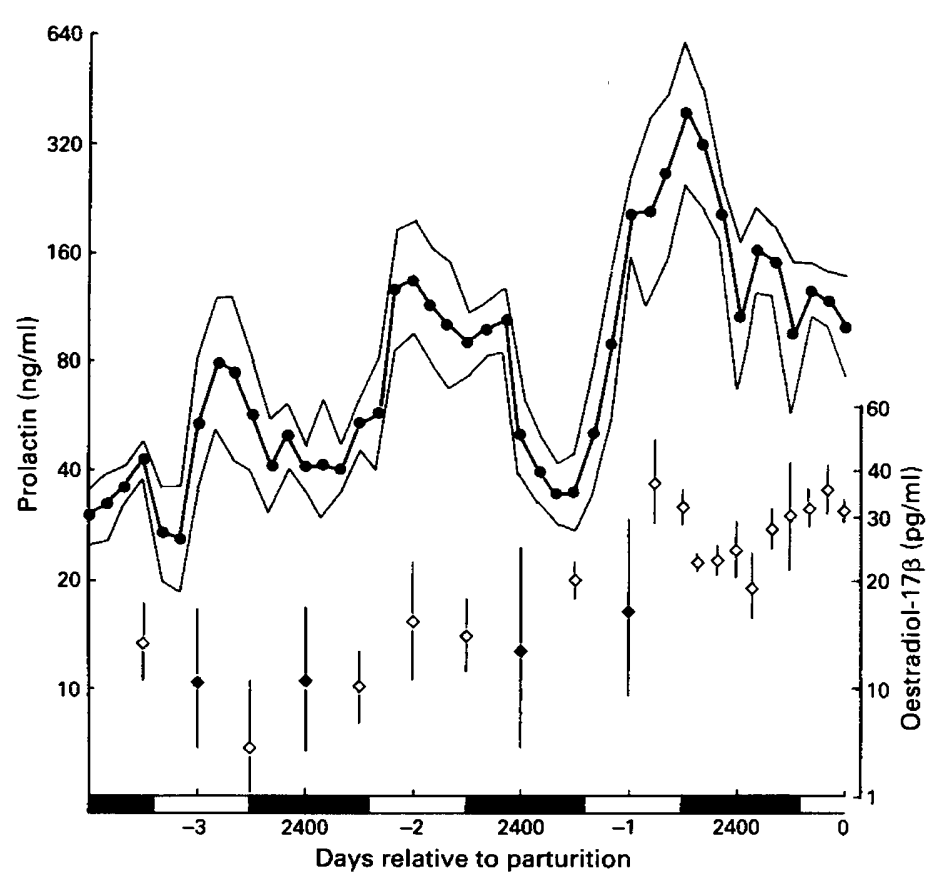

Fig. 1. Pre-partum changes in plasma concentrations of prolactin $(\odot)$ and oestradiol-17 $\beta$ $(\diamond \diamond)$ in 6 goats before parturition at term. Samples were taken every $2 \mathrm{~h}$ and the day and night intervals, each approximately $12 \mathrm{~h}$, are shown with all animals delivering their young some time during Day 0. Prolactin concentrations were measured in all samples; oestradiol-17 $\beta$ was measured 4 times daily until the last $24 \mathrm{~h}$. Data are shown as geometric means with standard errors of the log-transformed values. Note the logarithmic ordinates. When measured concentrations of oestradiol-17 $\beta$ were zero, a value of $1 \mathrm{pg} / \mathrm{ml}$ was substituted and the resultant means are shown as closed symbols $(\diamond)$.

from this animal were rejected from the analyses as they could not be timed precisely with reference to parturition.

\section{Oestradiol-17ß}

Before the 4th day before parturition, plasma concentrations of oestradiol-17 $\beta$ were usually at or lower than the sensitivity of the assay. During the 4th day, measurable concentrations were detected in most samples and virtually all samples collected thereafter contained oestradiol-17\%. Mean concentrations increased steadily, from $\sim 10 \mathrm{pg} / \mathrm{ml} 3$ days before parturition to about $35 \mathrm{pg} /$ $\mathrm{ml}$ on the day of parturition. There was some variation in the pattern of change for individual animals, especially during the last day. However, the results shown in Fig. 1, indicating an approximately $36-h$ doubling time for the mean concentrations, adequately describes the changes that were apparent for individual animals (from multiple regression analysis, data not shown).

Additional acute increases in concentrations were evident during labour with a mean of $58.7 \pm 4.3 \mathrm{pg} / \mathrm{ml}$ (range $31-83 \mathrm{pg} / \mathrm{ml}$ ) being measured in samples collected during the hour bracketing delivery of the first young from each goat. These periparturient changes cannot be discerned in Fig. I because of the time axis; some animals delivered in the last morning shown, with the remainder during the afternoon, so they are not shown. The final changes in oestradiol-17 $\beta$ with the completion of labour can be obtained from Fig. 2. 


\section{Prolactin}

Prolactin concentrations varied in no consistent fashion, with a range of 15 to $35 \mathrm{ng} / \mathrm{ml}$, before the 3rd day before parturition. As shown in Fig. 1, an overall increase in concentrations was evident during the last 3 days and a very pronounced rhythm was apparent. Peak concentrations were present during the afternoon hours and these values increased day by day until the day before parturition; $78 \cdot 8,135.4$ and $387 \mathrm{ng} / \mathrm{ml}$ (Days $-3,-2$ and -1 , respective geometric means). The duration of each cycle of elevated concentrations also appeared to increase with the approach of parturition. Nadir concentrations were measured during the nights with no obvious increase over the mean value on Day -4 , except during the last night when concentrations remained high at the pre-partum level of about $100 \mathrm{ng} / \mathrm{ml}$.

Peak concentrations on the afternoon before parturition ranged from 196 to $3155 \mathrm{ng} / \mathrm{ml}$, an exceedingly high value that was obtained from an animal carrying triplets. This animal also had the highest concentrations of oestradiol- $17 \beta$ of all animals on the day before parturition. Two other animals, one bearing twins and the other a single fetus, had prolactin measurements exceeding $1000 \mathrm{ng} / \mathrm{ml}$ on the day before parturition. Despite this range of values, the pattern shown by the geometric means in Fig. 1 was evident in the serial observations for each animal. Concentrations were always elevated during the day and returned to near the 'basal' values during each night except the last before parturition. Because the oscillations between peak and nadir concentrations increased in magnitude day by day, no attempt was made to fit a regression to all of the data. Nevertheless, the peak concentrations approximately doubled each day.

\section{Progesterone, PGFM and oestradiol-17 $\beta$}

Changes in jugular plasma concentrations of progesterone, PGFM and oestradiol-17 $\beta$ are shown in Fig. 2, plotted as means with respect to time before parturition. Concentrations of progesterone began to change gradually about $40 \mathrm{~h}$ before parturition but greater physiological importance is attached to the decrease evident at $-24 \mathrm{~h}$. Earlier fluctuations, displayed by all animals, did not lead to irreversible decreases whereas the decline detected at -26 to $-20 \mathrm{~h}$ for the individuals was not followed by any recovery. Concentrations were $<1 \mathrm{ng} / \mathrm{ml}$ in all animals during the last $12 \mathrm{~h}$ before parturition. The oestradiol-17 $\beta$ data are from the raw values used in Fig. 1 but are grouped here, without transformation, on the basis of time before parturition.

Jugular concentrations of PGFM fluctuated between 150 and $500 \mathrm{pg} / \mathrm{ml}$ in samples collected before about $48 \mathrm{~h}$ before parturition. A steady increase in PGFM values occurred during the last $36 \mathrm{~h}$ with values exceeding $1000 \mathrm{pg} / \mathrm{ml}$ by about $-24 \mathrm{~h}$. Exceedingly high concentrations were measured during labour (see inset in Fig. 2) and, at the moment of delivery, concentrations were $26 \cdot 5 \pm 4 \cdot 2 \mathrm{ng} / \mathrm{ml}$, a 50 -fold increase having occurred over the previous 2 days.

During the interval between -72 and $-12 \mathrm{~h}$ before parturition, a strong correlation was evident in the changes in oestradiol-17 $\beta$ and PGFM (Fig. 3a). With the exception of 1 goat, the correlation between the mean values $(r=0.83)$ was generally evident on a within-animal basis. Over the total pre-partum interval, including advanced labour, changes in PGFM related closely to the ratio of the means of oestradioi-17 $\beta$ to progesterone (Fig. 3b). However, comparable patterns were not always obvious in individual goats, so no correlation was computed for the mean values.

\section{Oxytocin}

The oxytocin data are shown only for the last $60 \mathrm{~min}$ before delivery of the first fetus (Fig. 4). Because timing is retrospective, the observations were quite unbalanced and no attempt was made to group the data. All measurements made earlier than $-120 \mathrm{~min}$ were at a basal level, that is $<15 \mu \mathrm{U} / \mathrm{ml}$. Samples collected within the last $60 \mathrm{~min}$ contained oxytocin in concentrations in excess of the basal level. In general, a marked increase accompanied the later stages of labour with concentrations 10 - to 60 -fold greater than basal. Peak measured concentrations varied widely between individuals $(180-1570 \mu \mathrm{U} / \mathrm{ml})$ and mostly occurred within minutes either before or after 


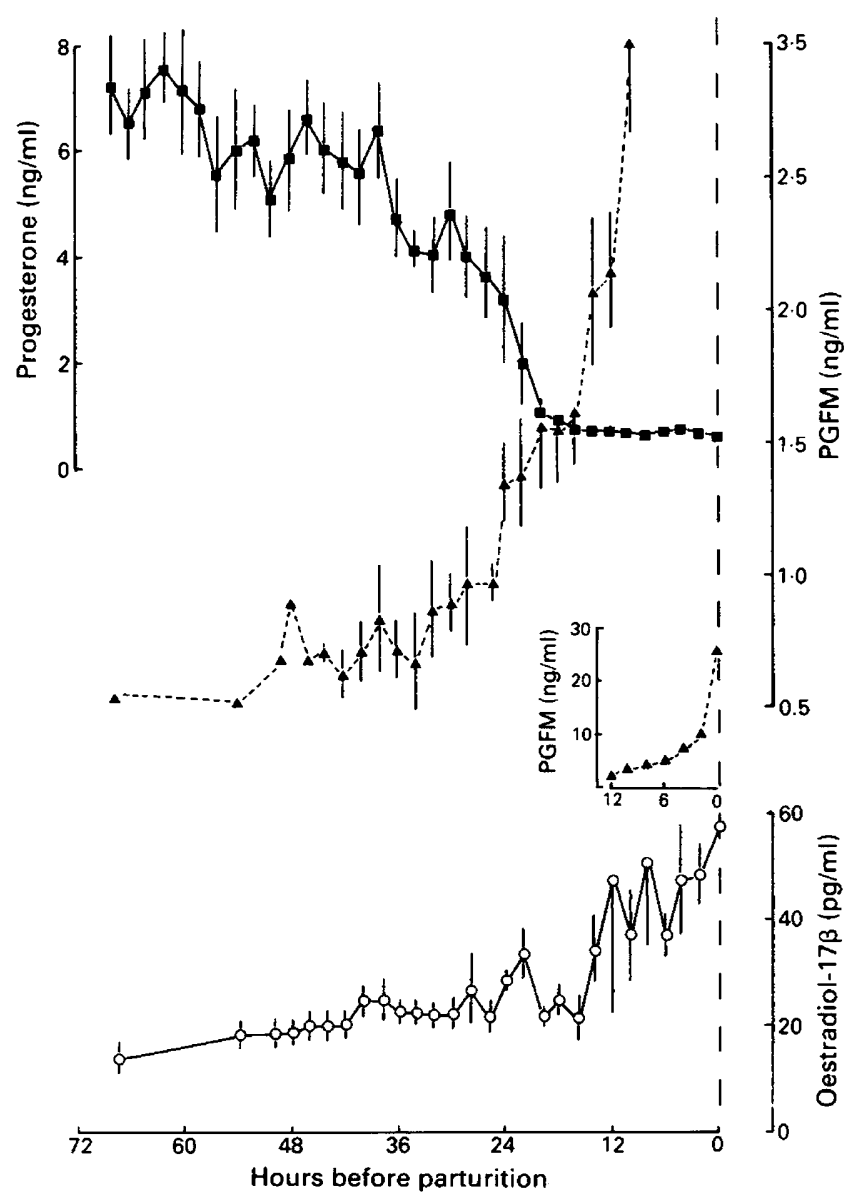

Fig. 2. Mean concentrations of progesterone ( $\boldsymbol{D}), \operatorname{PGFM}(\boldsymbol{\Delta})$ and oestradiol-17 $\beta(O)$ before spontaneous parturition at term in 6 goats. The data are means \pm s.e.m. $(n=6$ or 7$)$, except for the first 6 PGFM values for which the means are of 2 or 3 observations, or when twice the standard error was smaller than the size of the symbols (PGFM, last $6 \mathrm{~h}$ in inset).

the moment of delivery. Samples collected as frequently as every $30 \mathrm{sec}$ during labour, although not shown for reasons of obscuring the figure, revealed substantial fluctuations in concentrations, suggesting that oxytocin was being secreted in a series of bursts throughout the delivery phase of labour.

One animal (Goat 239) showed an atypical pattern of change in oxytocin, presumably associated with the malpresentation dystocia. The snout and one hoof of the fetus were visible at the vulva for $\sim 50 \mathrm{~min}$ but there was no manual contact by the observers during this time other than for the collection of blood from the catheter. The fetus was eventually repositioned and delivered with traction at time zero, as indicated on the figure.

No systematic analysis was applied to the oxytocin data and, because of multiple deliveries in many cases, there is no clearly discernible pattern of change after delivery of the first young.

\section{Discussion}

A pre-partum increase has been described for total unconjugated oestrogens (Challis \& Linzell, 1971; Davies et al., 1979), for unconjugated and sulphoconjugated oestrone and oestradiol-17 $\beta$ 

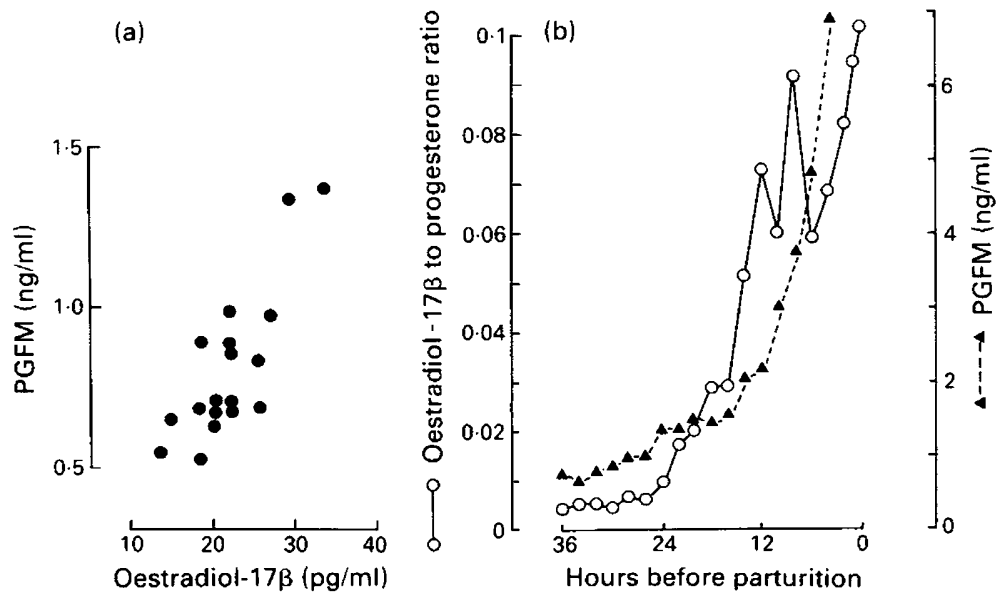

Fig. 3. Relationship between plasma concentrations of PGFM and oestradiol-17 $\beta$, or the relative amounts of oestradiol-17 $\beta$ and progesterone: (a) mean PGFM and oestradiol-17 $\beta$ values over the 2-day interval during which pre-partum luteolysis occurs; (b) changes in PGFM ( $\Delta$ ) and the relative concentrations of oestradiol- $17 \beta$ to progesterone $(O)$.

(Thorburn et al., 1972; Currie et al., 1973), and for oestradiol-17ß (Umo et al., 1976; Flint et al., 1978; Davies et al., 1979). In the last 3 studies, radioimmunoassays for oestradiol were used to measure utero-ovarian (Umo et al., 1976) or jugular venous samples. The present findings of a sustained increase in concentrations of unconjugated oestradiol-17 $\beta$ throughout the last 3 days are at variance with those of Umo et al. (1976) who detected no change over the last 8 days of pregnancy in 4 goats. Their mean concentrations are 10 -fold in excess of the present values; part of this difference is due to the gradient in concentrations from utero-ovarian to peripheral plasma (Thorburn et al., 1972) and up to $25 \%$ of their oestradiol-17 $\beta$ values could be due to the crossreactivity of their antiserum to oestradiol-17 $\alpha$.

Our results are more comparable to those of Flint et al. (1978) and Davies et al. (1979) who found an increase in jugular concentrations of oestradiol- $17 \beta$ from about $90 \mathrm{pg} / \mathrm{ml}$ at Day -4 to between 160 and $220 \mathrm{pg} / \mathrm{ml}$ shortly before parturition. Again, the sizeable difference in measured concentrations from those obtained in the present work could reflect use by Flint et al. (1978) of an antiserum known to cross-react $36 \%$ with oestradiol-17 $\alpha$; Davies et al. (1979) state that this cross-reactivity was $<1 \%$, but provide no details.

Despite the qualifications noted regarding comparability of these sets of data, there is agreement that the goat does not exhibit an acute pre-partum increase in unconjugated oestradiol-17 $\beta$ of the great magnitude known for sheep. The present results indicate that concentrations steadily increase about 5 -fold over the last 3 days. The change presumably reflects hypercortisolism in the maturing fetus in goats just as it does in sheep (Thorburn et al., 1972; Liggins et al., 1973). Flint et al. (1978) demonstrated that the goat placenta acquires the ability to transform progesterone via $17 \alpha$-hydroxyprogesterone to androgens and thence oestrogens during the period when the placenta is under the influence of fetal glucocorticosteroids. The correspondence between oestradiol-17 $\beta$ and PGFM changes around the time when luteal regression occurs supports our suggestion (Currie \& Thorburn, 1977b) that maturational events in the conceptus are linked to luteolysis because increased quantities of oestrogens are synthesized and are capable of releasing PGF.

Peripheral concentrations of PGFM begin to increase about $48-36 \mathrm{~h}$ before parturition. The increase accelerates from about $-24 \mathrm{~h}$ and the final increase during advanced labour and delivery is very striking. Concentrations of progesterone begin to decline as the PGFM started to increase 


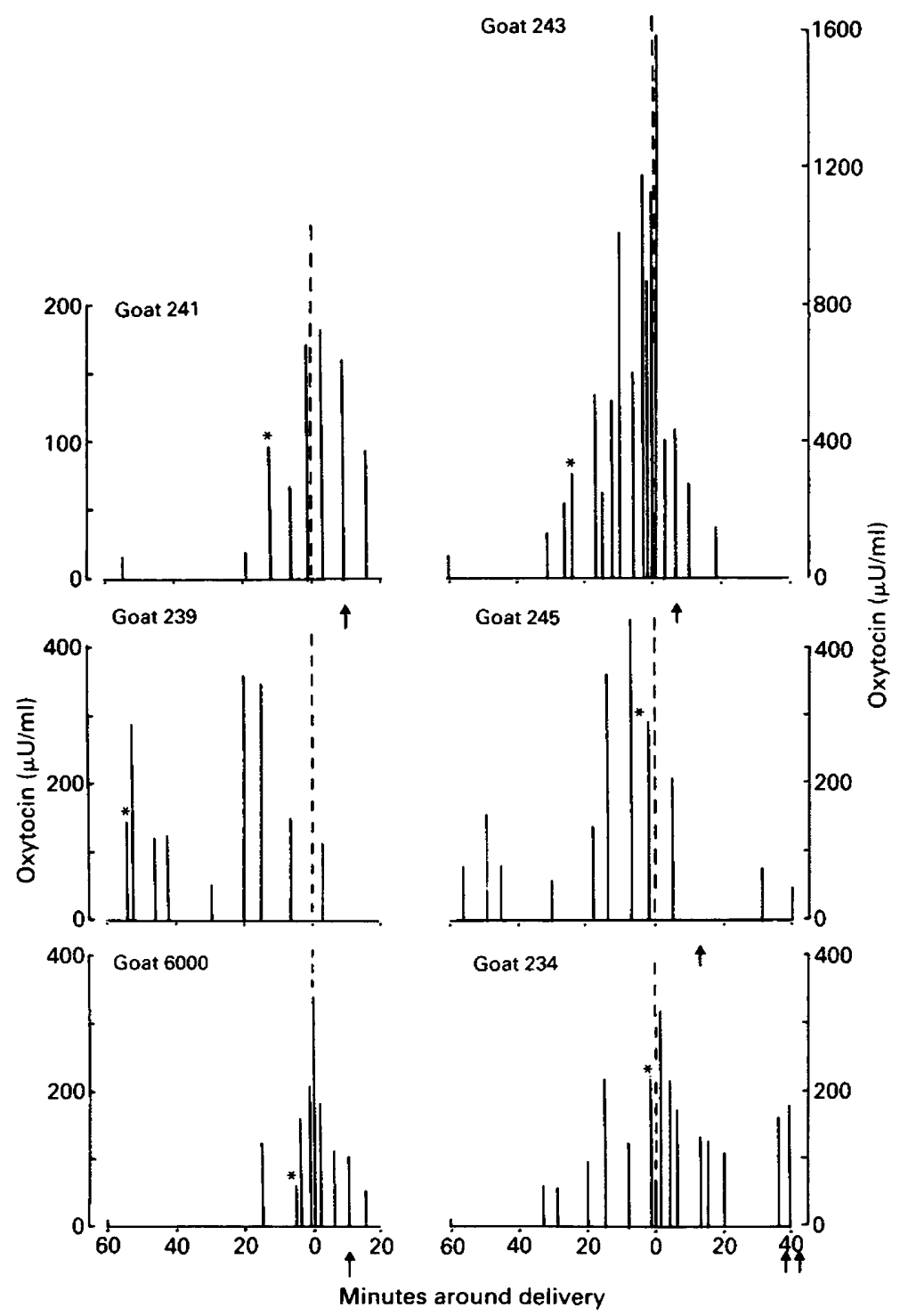

Fig. 4. Patterns of secretion of oxytocin in jugular plasma during advanced labour and delivery in 6 goats. The time scale is in minutes before and after delivery of the first fetus ( 0 time; broken line); subsequent deliveries are shown by the arrows. The time of appearance of the allantochorion is shown $\left({ }^{*}\right)$. Goat 239 suffered a forelimb dystocia which was not corrected until the fetus was manually extracted at time 0 .

and the irreversible decline in progesterone corresponded to the start of the more rapid change in PGFM which paralleled the relative amounts of oestradiol-17 $\beta$ to progesterone present in the circulation (Fig. 3b).

Earlier changes in PGFM relate closely to increased secretion of oestradiol-17 $\beta$. Oestradiol$17 \beta$, but not the $\alpha$-epimer, administered exogenously to goats late in pregnancy, provokes PGF secretion regression of the corpora lutea, a withdrawal of circulating progesterone, and finally parturition (Currie et al., 1976). Despite the considerable excess of oestradiol-17a over oestradiol- 
$17 \beta$, this finding suggests that changes in the $\beta$-epimer are likely to be of greater physiological moment.

The nature of the pre-partum increase in prolactin secretion is intriguing and, in part, was unexpected. That the increase occurred over the same time-course as did the increase in oestradiol$17 \beta$ is not surprising and both hormones are presumably responsible for the gradual increase in mammary turgor and hyperaemia normally observed over the 3-4 days before parturition. More copious secretion and pronounced engorgement of the mammae are evident during the last $24 \mathrm{~h}$ before delivery, corresponding to the lactogenic trigger of the abrupt and near complete removal of progesterone over this interval (Currie \& Thorburn, 1977a, b; discussed in detail by Davies et al., 1979). It is well known that prolactin secretion is sensitive to prevailing light conditions; both circadian and circannual patterns of change in concentration have been described for most species. The management and sampling of the animals in the present study was not aimed at defining such rhythms because the barn was dimly illuminated throughout the sampling period. The animals had been under normal environmental lighting throughout pregnancy and presumably were entrained to the late winter conditions when they entered the study. There was, however, no indication of any distinct rhythm in plasma prolactin concentrations during the days and nights preceding those shown in Fig. 1. During the last 3 days, a clear indication of diurnal change was obtained along with a progressive increase in the magnitude of the daily oscillations and apparently in the duration of each secretory phase.

We suggest that oestradiol- $17 \beta$ is responsible for regulating the unusual pattern of prolactin secretion in goats during the pre-parturient period. There was no indication of any rhythm in concentrations of oestradiol-17 $\beta$. These results, considered in the light of our earlier observations of lactogenesis, luteolysis and parturition after administration of oestradiol-17 $\beta$ to pregnant goats (Currie et al., 1976), support the notion that oestradiol-17 $\beta$ serves as a key communicator between the maturing conceptus and the mother. The present observations may be consistent with a role for oestradiol-17 $\beta$ in regulating the set-points governing sensitivity of the hypothalamo-pituitary axis to the other factors controlling the rhythm in prolactin secretion.

The secretory patterns of oxytocin are noteworthy because of the striking differences now becoming apparent between species. In these goats, oxytocin was released in amounts exceeding basal rates of secretion for as much as $90 \mathrm{~min}$ before delivery. Substantial increases in oxytocin were detected as early as $15 \mathrm{~min}$ before appearance of the allantochorion. As we intentionally avoided performing vaginal examinations, it is not possible to comment on the degree of distension of the cervix or anterior vagina when oxytocin secretion appeared to accelerate. The one animal with dystocia had an atypical pattern of change in oxytocin and was making strenuous efforts to deliver throughout the period when concentrations were elevated. We presume that there was reflex stimulation from distension throughout this period. In the remaining goats, peak concentrations of oxytocin corresponded closely to presumptive maximal distension of the tract, either by nonruptured allantochorionic sacs or by the crown of the fetal head. Similar findings were obtained by McNeilly et al. (1972) although our measured concentrations were generally higher and grossly higher in the case of one animal. Plasma samples containing in excess of $1000 \mu \mathrm{U} / \mathrm{ml}$ were subjected to gel filtration chromatography and oxytocin immunoreactivity was recovered quantitatively with elution characteristics identical to those of synthetic oxytocin (data not shown).

Our data suggest that parturient goats secrete oxytocin throughout advanced labour and not just as a single bolus-type release as others (Schams \& Prokopp, 1979) and we (W. B. Currie, R. C. Gorewit \& M. L. Thonney, unpublished results) have observed in cattle. Sustained secretion of oxytocin throughout delivery has also been found in pony mares (Haluska, 1985), in rabbits (Fuchs \& Dawood, 1980) and in miniature swine (Forsling et al., 1979).

There is general consensus that there is no obvious increase in oxytocin concentrations responsible for the initiation of labour in the species listed above. However, the widespread occurrence of increased rates of oxytocin secretion for several minutes before parturition is strongly suggestive of oxytocin serving finally to precipitate delivery. 


\section{References}

Butler, W.R., Krey, L.C., Lu, K-H., Peckham, W.D. \& Knobil, E. (1975) Surgical disconnection of the medial basal hypothalamus and pituitary function in the Rhesus monkey. IV. Prolactin secretion. Endocrinology 96, 1099-1105.

Buttle, H.L., Forsyth, I.A. \& Knaggs, G.S. (1972) Plasma prolactin measured by radioimmunoassay and bioassay in pregnant and lactating goats and the occurrence of a placental lactogen. $J$. Endocr. 53, 483-491.

Challis, J.R.G. \& Linzell, J.L. (1971) The concentration of total unconjugated oestrogens in the plasma of pregnant goats. J. Reprod. Fert. 26, 401-404.

Cooke, R.G. \& Homeida, A.B. (1982) Plasma concentrations of 13,14-dihydro-15-keto-prostaglandin $\mathrm{F}_{2 a}$ and progesterone during oxytocin-induced oestrus in the goat. Theriogenology 18, 453-460.

Currie, W.B. \& Thorburn, G.D. (1977a) Parturition in goats: studies on the interactions between the foetus, placenta, prostaglandin $\mathrm{F}$ and progesterone before parturition, at term or at parturition induced prematurely by corticotrophin infusion of the foetus. $J$. Endocr. 73, 263-278.

Currie, W.B. \& Thorburn, G.D. (1977b) The fetal role in timing the initiation of parturition in the goat. In The Fetus and Birth (Ciba Fndn Symp. No. 47), pp. 47-66. Eds J. Knight \& M. O'Connor. Elsevier, Amsterdam.

Currie, W.B., Wong, M.S.F., Cox, R.I. \& Thorburn, G.D. (1973) Spontaneous or dexamethasone-induced parturition in the sheep and goat: changes in plasma concentrations of maternal prostaglandin $\mathbf{F}$ and foetal oestrogen sulphate. Mem. Soc. Endocr. 20, 95-118.

Currie, W.B., Cox, R.I. \& Thorburn, G.D. (1976) Release of prostaglandin $F$, regression of the corpora lutea and induction of premature parturition in goats treated with oestradiol-17ß. Prostaglandins 12, 1093-1103.

Davies, A.J., Fleet, I.R., Goode, J.A., Hamon, M.H., Maule-Walker, F.M. \& Peaker, M. (1979) Changes in mammary function at the onset of lactation in the goat: correlation with hormonal changes. J. Physiol., Lond. 288, 33-44.

Fitzgerald, J. \& Butler, W.R. (1982) Seasonal effects and hormonal patterns related to puberty in ewe lambs. Biol. Reprod. 27, 853-863.

Flint, A.P.F., Kingston, E.J., Robinson, J.S. \& Thorburn, G.D. (1978) Initiation of parturition in the goat: evidence for control by foetal glucocorticoid through activation of placental $\mathrm{C}_{21}$-steroid $17 \alpha$-hydroxylase. J. Endocr. 78, 367-378.

Forsling, M.L., Macdonald, A.A. \& Ellendorff, F. (1979) The neurohypophyseal hormones. Anim. Reprod. Sci. 2, 43-56.

Freeman, L.C. \& Currie, W.B. (1985) Variation in the oxytocin content of caprine corpora lutea across the breeding season. Theriogenology 23, 482-486.

Fuchs, A.-R. \& Dawood, M.Y. (1980) Oxytocin release and uterine activation during parturition in rabbits. Endocrinology 107, 1117-1126.
Gorewit, R.C. (1979) Method for determining oxytocin concentrations in unextracted sera; characterization in lactating cattle. Proc. Soc. exp. Biol. Med. 160, 80-87.

Haluska, G.J. (1985) Electromyographic analysis of the myometrium of the mare correlated with the endocrinology of pregnancy, parturition and the postpartum period. Ph.D. thesis, Cornell University.

Hart, I.C. (1972) A solid phase radioimmunoassay for ovine and caprine prolactin using Sepharose 6B: its application to the measurement of circulating levels of prolactin before and during parturition in the goat. J. Endocr. 55, 51-62.

Korenman, S.G., Stevens, R.H., Carpenter, L.A., Robb, M., Niswender, G.D. \& Sherman, B.M. (1974) Estradiol radioimmunoassay without chromatography: procedure, validation and normal values. J. clin. Endocr. Metab. 38, 718-720.

Liggins, G.C., Fairclough, R.J., Grieves, S.A., Kendall, J.Z. \& Knox, B.S. (1973) The mechanism of initiation of parturition in the ewe. Recent Progr. Horm. Res. 29, $111-159$.

McNeilly, A.S. \& Andrews, P. (1974) Purification and characterization of caprine prolactin. $J$. Endocr. 60, 359-367.

McNeilly, A.S., Martin, M.J., Chard, T. \& Hart, I.C. (1972) Simultaneous release of oxytocin and neurophysin during parturition in the goat. $J$. Endocr. 52, 213-214.

Olson, D.M. \& Hertelendy, F. (1981) Plasma levels of 13,14-dihydro-15-keto-prostaglandin $F_{\alpha}$ in relation to oviposition and ovulation in the domestic hen (Gallus domesticus). Biol. Reprod. 24, 496-504.

Schams, D. \& Prokopp, S. (1979) Oxytocin determination by RIA in cows around parturition. Anim. Reprod. Sci. 2, 267-270.

Shiu, R.P.C., Kelly, P.A. \& Friesen, H.G. (1973) Radioreceptor assay for prolactin and other lactogenic hormones. Science, N.Y. 80, 968-971.

Thorburn, G.D., Nicol, D.H., Bassett, J.M., Shutt, D.A. \& Cox, R.I. (1972) Parturition in the goat and sheep: changes in corticosteroids, progesterone, oestrogens and prostaglandin F. J. Reprod. Fert., Suppl. 16, 61-84.

Umo, I., Fitzpatrick, R.J. \& Ward, W.R. (1976) Parturition in the goat: plasma concentrations of prostaglandin $F$ and steroid hormones and uterine activity during late pregnancy and parturition. J. Endocr. 68, 383-389.

Wachs, E.A., Gorewit, R.C. \& Currie, W.B. (1984) Half-life, clearance and production rate of oxytocin in cattle during lactation and mammary involution. Domestic Anim. Endocr. 1, 121-140. 